\title{
TRADEOFFS OF AUSTRIAN BUDGETARY POLICIES: AN OPTIMUM CONTROL ANALYSIS
}

\author{
Reinhard Neck ${ }^{1}$ and Harald Stieber ${ }^{2}$ \\ ${ }^{1}$ Department of Economics, University of Klagenfurt, \\ Universitätsstrasse 65-67, A-9020 Klagenfurt, Austria \\ ${ }^{2}$ Economics Department, Austrian Federal Ministry of Finance, \\ Himmelpfortgasse 4-8, A-1015 Vienna, Austria
}

\begin{abstract}
In this paper, we use optimum control methods to determine optimal budgetary policies for Austria over a five-year horizon. Optimal fiscal policies are calculated using the algorithm OPTCON. Optimal policies are compared to a simulation using extrapolated values of budgetary policy variables in terms of their performance with respect to Austrian macroeconomic targets. Policy tradeoffs between these variables are quantified. Copyright C 2005 IFAC
\end{abstract}

Keywords: optimal control, economics, optimization, policy, econometric model.

\section{INTRODUCTION}

Optimum control methods have been used in various studies to determine optimal intertemporal decisions for many small models in economics and business. For actual problems of policy-making at the macroeconomic level, however, an analytical approach has only limited relevance, because these problems are usually characterized by a great number of relevant variables and constraints, which can only be captured in a model of medium or large size. Moreover, when optimal policies for macroeconomic decision problems have to be determined, there is considerable uncertainty about policy-makers' actual preferences. Therefore, numerical methods of dynamic optimization are the only means to solve problems of actual macroeconomic policy-making.

In this paper, we use an algorithm for determining optimal policies for nonlinear dynamic models to deal with the problem of designing optimal budgetary policies for Austria. This issue is of great political relevance, because Austria as a member of the European Economic and Monetary Union (EMU) is obliged to design its fiscal policies in such a way as to avoid pro-cyclical policies, excessive deficits and excessive levels of gross public debt. More precisely, Austria has to aim at reducing the level of gross public debt (general government sector) as a ratio of actual GDP to less than $60 \%$ (and further on to a level that is sustainable in the long run, taking into account the budgetary costs of ageing), while the public debt-GDP ratio was 65\% in 2003.

Here we choose an approach of quantitative economic policy to determine numerically optimal budgetary policies for the next few years by minimizing an intertemporal objective function subject to the constraints given by an econometric model. This model, called FINPOL4, is a mediumsize macro-econometric model for Austria, relating policy and exogenous variables to objective variables of Austrian economic policies. The objective function penalizes deviations of objective variables from their desired ("ideal") values. Exogenous variables of the model are forecast over the planning horizon using time series methods. Optimal fiscal policies are calculated using the optimum control 
algorithm OPTCON. Optimal policies are compared to a simulation using extrapolated values of budgetary policy variables in terms of their performance with respect to Austrian macroeconomic targets. By varying the weights given to different target variables in the objective function, it is possible to determine quantitative tradeoffs between these variables.

\section{THE ECONOMETRIC MODEL FINPOL4}

The model FINPOL4 is based on traditional Keynesian macroeconomic theory in the sense of conventional IS - LM/aggregate demand - aggregate supply models. Stochastic behavioral equations for the demand side include a consumption function, an investment function, an import function and an interest-rate equation as a reduced-form money market model. Prices are largely determined by aggregate demand variables. Disequilibrium in the labor market, as measured by the excess of unemployed persons over vacancies, is modeled to depend on the real GDP growth rate and the rate of inflation, embodying both an Okun's law-type relation and a rudimentary Phillips curve. The main objective variables of Austrian economic policies, such as real GDP, the labor market disequilibrium variable (related to the rate of unemployment), the rate of inflation, the balance of payments and the ratio of the federal net budget deficit to GDP, are related directly or indirectly to those fiscal policy instruments which are used as control variables, namely to federal budget expenditures and revenues.

The model, which is dynamic and nonlinear, was estimated first by OLS and then by simultaneous equations estimation methods using annual data over the period 1976 to 2001. Data were obtained from the Austrian Institute of Economic Research (WIFO). In the version used here, the behavioral equations of the model were estimated by three-stage leastsquares and simulated using the software TSP 4.5. The estimates and test statistics together with ex-post simulation results suggest that the model provides a reasonable account of the development of economic variables in the recent past. The variables used and the estimation results are given below, omitting statistical characteristics for lack of space.

\section{Model variables used in FINPOL4}

Endogenous variables (billions of euros if not stated otherwise):

$\begin{array}{ll}C R & \text { real private consumption } \\ I R & \text { real fixed investment } \\ M R & \text { real imports of goods and services } \\ R & \text { nominal rate of interest (long-term bond } \\ & \text { yield), \% } \\ Y R & \text { real gross domestic product at } 1995 \text { prices } \\ V R & \text { real total aggregate demand }\end{array}$

$P V \quad$ general price level (total demand deflator), index, $1995=100$

$Y D R \quad$ real disposable personal income

$I N F L \quad$ rate of inflation, $\%$

$R R \quad$ real rate of interest, \%

$M 1 R \quad$ real stock of money supply M1

$P Y \quad$ domestic price level (deflator of GDP at market prices), index

UN labor market excess supply (unemployed minus vacancies as percentage of dependent labor force), $\%$

WRYR growth rate of real GDP at market prices, $\%$

LBR real current account (real exports minus real imports of goods and services)

$G R \quad$ real public consumption

$T R$ real public sector net tax revenues (including social insurance contributions)

$P G \quad$ deflator of public consumption, index

$V \quad$ nominal total aggregate demand

$G$ nominal public consumption

$T \quad$ nominal public-sector net tax revenues

$D E F \quad$ federal net budget deficit

$D E F Q$ federal net budget deficit as percentage of GDP, \%

$Y \quad$ nominal GDP at market prices

$F D$ federal government debt

$F D Q \quad F D$ as percentage of GDP, \%

$L B R Q \quad L B R$ as percentage of GDP, \%

$W R V R \quad$ growth of real total demand, \%

Control variables:

NEX federal budget net expenditures

$B I N \quad$ federal budget tax revenues

Exogenous non-controlled variables:

$X R \quad$ real exports of goods and services

IIR real inventory changes (including errors and omissions from the NA statistics)

$P M \quad$ import price level, index

M1 nominal stock of money supply M1

$D X D \quad$ autonomous federal public debt changes

Model equations

Consumption equation

$C R=0.2972 C R_{-1}+0.4969 Y D R-37.3319$

Investment equation

$I R=0.4349 I R_{-1}+0.6405 Y R-0.5078 Y R_{-1}$

$-9.8656 R R+27.0041$

Import equation

$M R=0.5544 M_{-1}+0.2604 V R-1.9125 P M$ $-100.8960$

Interest rate equation

$R=0.4114 R_{-1}-0.0156 M 1 R+0.0060 Y R$ +0.5702 INFL -1.9439

GDP identity 
$Y R=C R+I R+G R+X R+I I R-M R$

Aggregate demand identity

$V R=Y R+M R$

Total demand deflator identity

$P V=Y R / V R \cdot P Y+M R / V R \cdot P M$

Personal disposable income identity

$Y D R=Y R-T R$

Inflation rate identity

$I N F L=\left(P V-P V_{-1}\right) / P V_{-1} \cdot 100$

Real interest rate identity

$R R=R-I N F L$

Money supply identity

$M 1 R=M 1 / P V \cdot 100$

Domestic price level equation

$P Y=0.8255 P Y_{-1}+0.0045 Y R+0.1102 P M$ $-0.5730$

Labor market excess supply equation $U N=0.7622 U N_{-1}-0.1206 W R V R$ $-0.1645 I N F L+1.7111$

Real GDP growth identity

$W R Y R=\left(Y R-Y R_{-1}\right) / Y R_{-1} \cdot 100$

Real current account identity

$L B R=X R-M R$

Public consumption identity

$G R=G / P G \cdot 100$

Real tax revenues identity

$T R=T / P Y \cdot 100$

Public consumption deflator equation

$P G=0.2757 P G_{-1}+0.7529 P Y+0.0074 Y R$

$-15.2737$

Nominal total aggregate demand identity

$V=V R \cdot P V / 100$

Nominal public consumption equation

$G=0.4994 G_{-1}+0.0549 Y_{-1}+0.1567 N E X$

Nominal public-sector tax revenues equation

$T=0.5171 T_{-1}+0.1211 B I N+0.0491 V R-41.5223$

Federal net budget deficit identity

$D E F=N E X-B I N$

Budget deficit-to-GDP ratio identity

$D E F Q=D E F / Y \cdot 100$

Nominal GDP identity

$Y=Y R \cdot P Y / 100$

Federal government debt identity
$F D=F D_{-1}+D E F+D X D$

$F D$ as percentage of GDP identity

$F D Q=F D / Y \cdot 100$

$L B R$ as percentage of GDP identity

$L B R Q=L B R / Y R \cdot 100$

Real growth of demand identity

$W R V R=\left(V R-V R_{-1}\right) / V R_{-1} \cdot 100$

\section{THE OPTIMUM CONTROL APPROACH}

In the theory of quantitative economic policy, macroeconomic policy problems are often considered as problems of optimizing an intertemporal objective function under the constraints of a dynamic system. Optimum control theory has been used in several studies to determine optimal policies for econometric models; e.g., Chow (1975, 1981), Kendrick (1981). Here we use the algorithm OPTCON, developed by Matulka and Neck (1992); it determines approximate solutions of deterministic or stochastic optimum control problems with a quadratic objective function and a nonlinear multivariable dynamic model. The objective function has to be quadratic in the deviations of the state and control variables from their respective desired values. The dynamic system is required to be given in a state space representation.

For our simulation experiments, we choose the planning horizon as 2002 to 2006. Among the variables whose deviations from desired values are to be penalized, we distinguish two categories: First, there are six "main" objective variables which are of direct political relevance in assessing the performance of the Austrian economy. These are the rate of inflation, the rate of (involuntary) unemployment, the rate of growth of real GDP, the current account, the federal government debt and the federal government net budget deficit (the latter three being measured as percentages of GDP). $2 \%$ p.a. is considered as the desired rate of inflation (in accordance with the official upper-bound target of the European Central Bank), 2.5\% p.a. as the desired real growth rate, and the desired levels for involuntary unemployment, the current account and the budget deficit are set equal to zero. For the debt variable, we assume that the aim is to reduce the stock of gross federal government debt by 1 percentage point of GDP each year.

Second, we introduce a category of "minor" objective variables. We take 2001 historical values of these "minor" objective variables to be given and postulate for all of them constant desired growth rates in accordance with the specification of the desired values of those "main" objective variables which are growth rates. This also serves to prevent unrealistic and undesirable fluctuations of these variables. The "minor" objectives also include the control variables. 
In the weight matrix of the objective function, all offdiagonal elements are set equal to zero, and the main diagonal elements are given (in the first experiment) weights of 1,000 for the "main" objective variables and of 1 for the "minor" objective variables. The other state variables get weights of zero, thus being regarded as irrelevant to the fiscal policy-maker. The weight matrix is assumed to be constant over time.

The algorithm OPTCON assumes the values of the non-controlled exogenous variables to be known in advance for all time periods of the planning horizon. For a simulation over a future planning horizon, projections (forecasts) of the exogenous (controlled and non-controlled) variables are needed. Here we use extrapolations of these variables for the years 2002 to 2006 calculated from linear stochastic time series models of the ARMA (mixed autoregressive moving average process) type in a similar way as in Neck and Karbuz (2002).

\section{SIMULATION AND OPTIMIZATION RESULTS}

As a first step, the model was simulated over the years 2002 to 2006, using the extrapolations of all (control and non-controlled) exogenous variables from the time series models as input. This amounts to a dynamic forecast of the endogenous variables of the model; no optimization is involved in this projection, which serves as a reference for comparison with the optimization runs. The results of this baseline simulation are shown for the main objective variables in Figure 1.

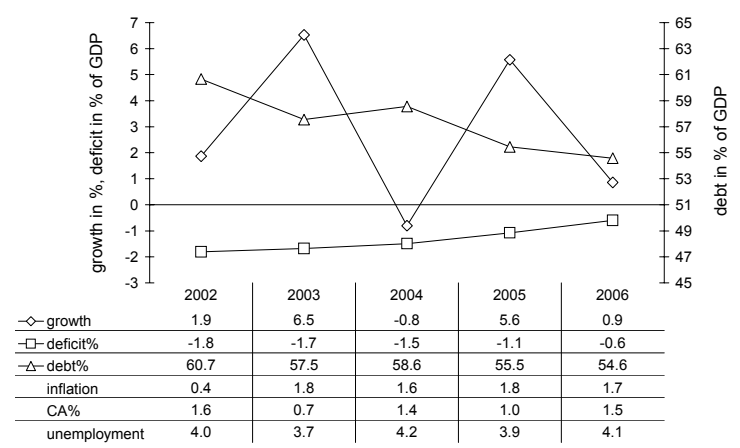

Fig. 1. Baseline solution

In accordance with international conventions, budget deficits (surpluses) are shown as negative (positive) numbers. The high volatility of real GDP in this simulation is partly due to the absence of dampening mechanisms relating to the current account and the labor market in the model FINPOL4. However, the simulated economy shows a reasonable behavior insofar as all the changes in the main variables have the correct sign. Higher real GDP growth is associated with lower budget deficits, higher inflation, a fall in the current account and a fall in unemployment.
Next, we performed an optimization experiment as detailed in the previous section. Here again the projections of the non-controlled exogenous variables from the time series models are used as inputs, being assumed to be known for certain, but the values of the policy instruments are determined endogenously as (approximately) optimal under the assumed objective function.

To begin with, we present the optimal solution to our problem with equal weights of 1,000 attached to all "major" economic target variables in the loss function being minimized (Figure 2). A comparison between the results of the simulation and of the optimum control experiments shows that there is some scope for optimal stabilization policy. In particular, optimal fiscal policies are more countercyclical than projected ones and imply smoother time paths of the endogenous variables of the model.

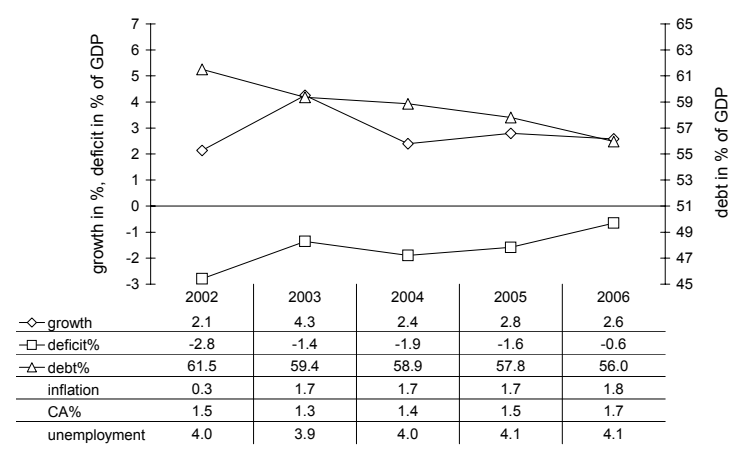

Fig 2. Optimal solution, all weights 1,000

In a next step, we investigated the behavior of the economy when we increase the weights on all or some of our six main economic target variables. Figure 3 shows that varying the weights of all six "major" target variables at the same time leads to different responses of the policy instruments (control variables) and the target variables.

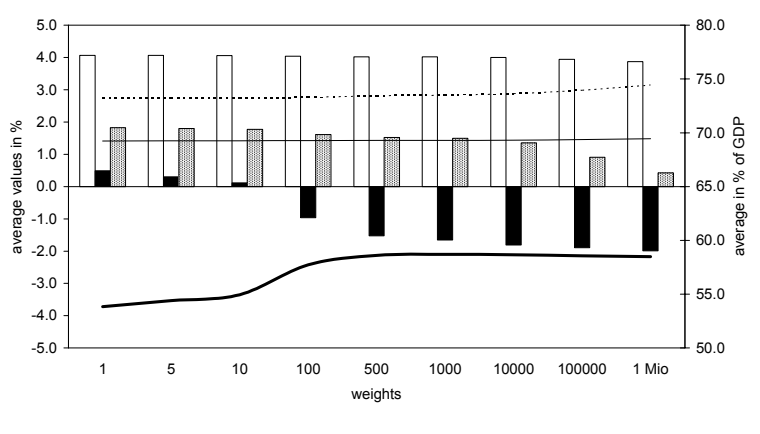

Fig. 3. Influence of weights on optimal results

There is a tradeoff between instruments (control variables) on the one hand and targets on the other. In particular, higher weights for the main targets imply more "active" (expansionary) fiscal policy actions, increasing federal budget expenditures and 
reducing tax revenues relative to the optimization runs with lower weights. This increases the budget deficit (and hence federal government debt) to raise slightly real GDP growth, which reduces the current account. The effects on unemployment and inflation are fairly small. Alternatively, we can say that the more the weights are increased, the more "Keynesian" the optimal solution gets. This becomes particularly clear from an inspection of the tradeoff between budget deficits and rates of real GDP growth (Figure 4). Higher weights on all "main" objective variables induce activist expansionary budgetary policies, which lead to high budget deficits with only modest rewards in terms of higher output.

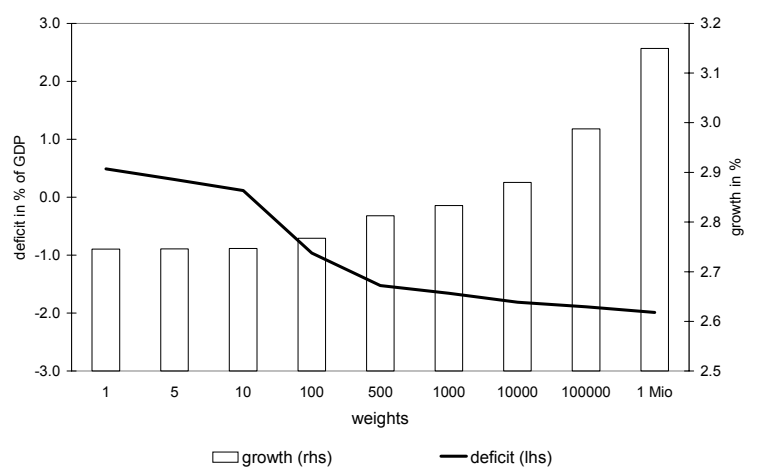

Fig. 4. Tradeoff between GDP growth and budget deficit (same weight to all "main" objectives in each case)

\section{QUANTIFYING POLICY TRADEOFFS}

Next, we consider tradeoffs between particular objectives of macroeconomic policy, which were discussed intensively in the literature. In particular, we are interested in the tradeoff between inflation and unemployment (the famous Phillips curve) and the tradeoff between the budget deficit (an increase of public debt) and economic growth. Of course, we are aware of the macroeconomic theoretical and empirical results indicating that both tradeoffs exist only in the short run, with long-run relations between these variables being completely different. In view of our Keynesian model, which is intended to analyze short-run policy effects and design (of no more than five years, say), however, these short-run tradeoffs are highly relevant to policy-makers.

To analyze these bilateral (ceteris paribus) tradeoffs, we distribute a constant amount of weight in the objective function between only two economic target variables, leaving all other weights on ("main" and "minor") objective variables constant (they are all set equal to one). Several optimum control experiments are carried out to obtain results for the objective function varied in such a way. Using the results, we can visualize tradeoffs between pairs of "main" economic target variables for a given level of total weight used in the optimization procedure. The resulting graphs contain information both from the policy-makers' preferences and from the model; they can best be interpreted as "policy possibility frontiers" and may be called "tradeoff curves" under alternative weights for particular objective variables. A similar question was treated by Chow and Megdal (1978), although for variations of the desired paths of the objective variables.

Two interesting tradeoffs are shown in Figures 5 and 6. We show the tradeoff for total weights set to 10,000 in the case of the unemployment - inflation tradeoff and 1,000 in the case of the deficit - growth tradeoff. The two curves do not show the same shape: Whereas the inflation-unemployment is almost perfectly linear, the deficit - GDP growth tradeoff is more nonlinear, especially when the weight on growth is increased. In particular, when more weight is given to one of these two variables, deviations from desired values are reduced relatively more successfully in the case of the budget deficit than in the case of GDP growth, showing the difficulty of raising real GDP growth by expansionary Keynesian fiscal policy.

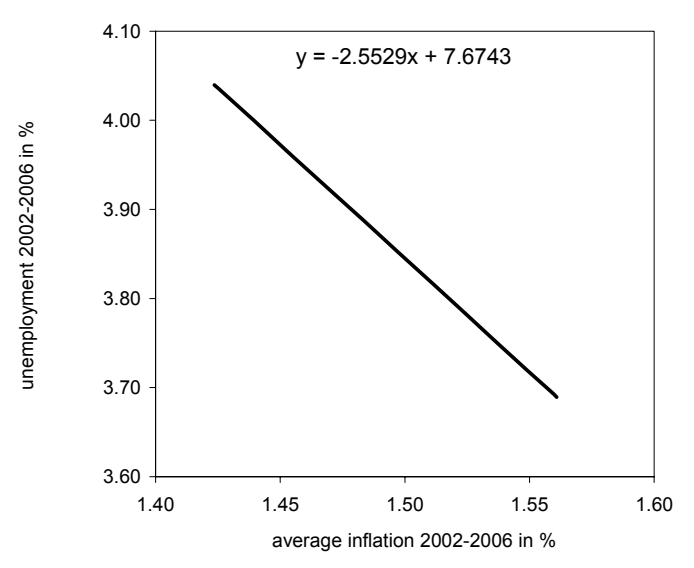

Fig. 5. Tradeoff between unemployment and inflation

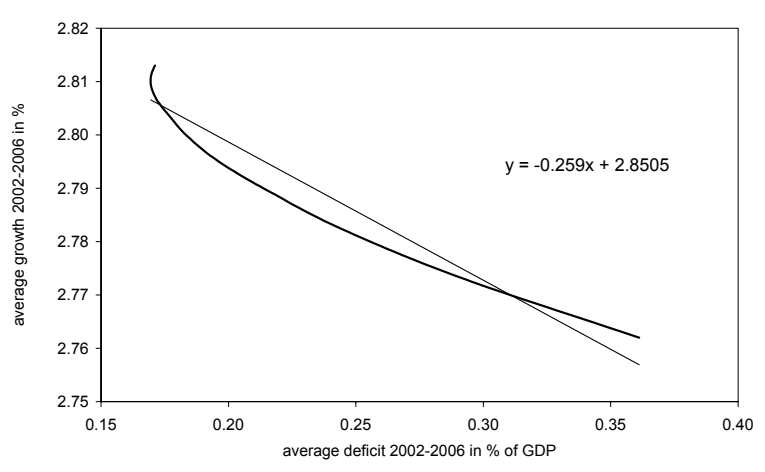

Fig. 6. Tradeoff between growth and budget deficit

The trade-off between inflation and unemployment corresponds to a naïve Phillips-curve where about 2.5 percentage of unemployment are traded for 1 percentage point of inflation (both measured over an 
average of five years). This tradeoff holds in the region of both variables delineated by the figure and may be different under alternative conditions (for example, under a hyperinflation or mass unemployment). Moreover, it corresponds to particular period averages and may change when the optimization is carried out over a longer or shorter period. This caveat notwithstanding, it is exactly this kind of information that is demanded in giving short-run policy advice.

The trade-off between the average real GDP growth rate and the average fiscal deficit implies a relation of about one to four. An additional percentage point of economic growth costs 4 more percentage points of the budget deficit. This value seems quite plausible, given the recent disillusion with Keynesian budgetary policies. Note that in our case, we are operating in a region of a budget that is in surplus on average. Again, it must be stressed that these are short-run tradeoffs; in the long run, budget deficits may have even negative (non-Keynesian) effects on real GDP and employment.

\section{CONCLUDING REMARKS}

Summing up, we can see that the method of modeling the decision problem of the fiscal policymaker by optimum control methods seems highly promising. Future version may include a more detailed model of the government budget, e.g. distinguishing between direct and indirect taxes, or between government expenditures for goods and services and transfers to households and business. Improved modeling of the current account (endogenizing exports and including competitiveness indices, for example) is also highly desirable.
Nevertheless, already with the present model we can inform policy-makers about their options in a more serious way than without the optimum control approach.

\section{ACKNOWLEDGEMENT}

Financial support from the Jubiläumsfonds of the Austrian National Bank (project no. 9152) is gratefully acknowledged. The views expressed in this paper do not necessarily reflect those of the Austrian National Bank or the Austrian Federal Ministry of Finance.

\section{REFERENCES}

Chow, G. C. (1975). Analysis and Control of Dynamic Economic Systems. Wiley, New York.

Chow, G. C. (1981). Econometric Analysis by Control Methods. Wiley, New York.

Chow, G. C. and S. B. Megdal (1978). An Econometric Definition of the InflationUnemployment Tradeoff. American Economic Review, 68, 446-453.

Kendrick, D. (1981). Stochastic Control for Economic Models. McGraw-Hill, New York.

Matulka, J. and R. Neck (1992). OPTCON: An Algorithm for the Optimal Control of Nonlinear Stochastic Models. Annals of Operations Research, 37, 375-401.

Neck, R. and S. Karbuz (2002). Optimal Budgetary Policies for Austria: A Stochastic Optimum Control Analysis. Journal of Management and Economics November 6, http://www.econ.uba.ar /servicios/publicaciones/journal6. 